\title{
Pre-service Teacher Education for Mental Health and Inclusion in Schools
}

\author{
Melanie-Anne Atkins, Susan Rodger \\ University of Western Ontario
}

\begin{abstract}
Pre-service teacher education in mental health and mental health literacy is essential to creating the conditions necessary to support the mental health and wellness of children and youth in schools. Many teachers report never having received any education about mental health, but recognize the importance of this knowledge in meeting the needs of their students in regular classrooms. This article describes the development of a completely online mental health course organized around five learning objectives and delivered in a large pre-service teacher education program in Canada. Next, this article presents the results of research to evaluate impact on the pre-service teacher education students. Results are organized into expected and unexpected learning outcomes. Implications for further research and practice are shared.
\end{abstract}

In this article we focus on the development, delivery, and evaluation of an online elective course in mental health education for pre-service teacher education students (henceforth referred to as "teacher candidates") in a Bachelor of Education program at a large Ontario faculty of education. The process was precipitated and supported by multiple factors: the prevalence of mental health disorders in Canada, new developments in teacher accreditation program guidelines regarding instruction about mental health, the lack of pre-service teacher education about mental health, the important role that teachers and schools can play in children's mental health, and the promising research demonstrating the benefits of providing mental health instruction and supports in schools, for both students and teachers.

Approximately $20 \%$ of school-aged children experience a mental illness or substance abuse problem in any given year (Adelman \& Taylor, 2000), and the majority 
of mental health problems begin in childhood (Kessler et al., 2005). Responding to this, the school-involved approach to child and youth mental health was developing and taking hold, as evidenced by the Transformation Agenda for child and youth mental health in Ontario (Government of Ontario, 2012) and the growing concern about child and youth mental health and lack of access to care (e.g., Santor, Short, \& Ferguson, 2009). In an important article about school mental health in Canada, Flett and Hewitt (2013) pointed out that statistics demonstrating the numbers of children experiencing mental health problems are under-reported, and further, do not include children and youth who are experiencing significant distress but for whom a diagnosis is not appropriate. Since most children and youth attend school, curriculum for teacher candidates that includes mental health is seen by many to provide a natural "bridge" to reach as many children and youth as possible. Most notably, this recommendation was made by the Ontario College of Teachers in their Program Accreditation Guidelines (Ontario College of Teachers, 2014), requiring that all teacher candidates learn about mental health.

This was a welcome development, considering the current authors had been part of a team conducting a national scan of pre-service mental health education, and found little was being offered (Rodger, Hibbert, \& Leschied, 2014). Action was recommended, as the growing body of literature was converging with evidence that including teachers as active members of a team approach to child and youth mental health could yield positive results (e.g., Weist, Lever, Bradshaw, \& Owens, 2013). Finally, research in teacher education and mental health was yielding compelling evidence regarding (a) effective approaches to developing and increasing mental health literacy and (b) the effects of poor mental health for both teachers and students (e.g., Arens \& Morin, 2016; Jorm, Kitchener, Sawyer, Scales, \& Cvetkovski, 2010; Oberle \& Schoenert-Reichl, 2016).

The mental health of teachers was also an emerging concern: Research has identified that $12 \%$ of new teachers leave the profession before completing their first year, $28 \%$ by the end of three years, and $41 \%$ by their fifth year (Ingersoll, Merrill, \& Stuckey, 2014). Stress and burnout are commonly reported as responses to teaching (Ellis \& Riel, 2014; Johnson et al., 2005). Therefore, we recognized that it was equally important to educate teacher candidates on how to take care of their own mental health, especially since "the expectations placed on beginning teachers are identical to those placed on very experienced teachers, a situation unheard of in other professions" (Crocker \& Dibbon, 2008, p. 117). This was also a theme in the study conducted by Rodger et al., 2014. Knowing the risks for new teachers, it is up to teacher education programs to provide them with the tools and knowledge necessary for self-care.

These events and understandings led to the development and delivery of an elective course on mental health literacy. Development involved reviewing existing research literature in the areas of child and youth mental health; school mental health frameworks; teacher roles, education, and expectations; and effective education for teacher candidates. Five foundational learning objectives were developed. 


\section{Learning Objective \#1}

\section{Candidates will learn about the mental health and wellness of children.}

More than ever, teachers are on the "front lines of mental health" (Weist et al., 2013), and their roles are changing as they are increasingly called upon to take their place supporting the mental health of their students. This is a role for which they feel inadequately prepared (Koller \& Bertel, 2006; Rothi, Leavey, \& Best, 2008; Santor et al., 2009), but also about which they are "unanimously keen to learn more" (Gowers, Thomas, \& Deeley, 2004, p. 419). Teacher candidates report learning about internalizing mental health symptoms (i.e., anxiety, depression, low self-esteem) mainly through practicum experiences and discussions with supervising teachers, rather than through formal teacher training in faculties of education (Bryer \& Signorini, 2011). Pre-service teacher education programs have been slow to respond to the need for education about mental health: A 2014 national scan of over 400 offerings at 66 teacher education programs in Canada found only two courses available to teacher candidates that reflected both the inclusive and evidence-based approaches by: promoting mental health for all students, rather than being limited to a "special education" curriculum; having a clearly stated goal to address mental health or emotional well-being; focusing on building relationships with families and students; and offering practical strategies for the classroom (Rodger et al., 2014).

Teacher competencies that create conditions for learning for all students are central in Weston, Anderson-Butcher, and Burke's (2008) model for teacher education, which was inclusive and supported school mental health approaches while featuring culturally relevant teaching practices, holistic perspectives, and developmentally appropriate approaches.

\section{Learning Objective \#2}

Candidates will learn about the impact of mental health in general (not restricted to specific disorders or diagnoses) on school performance and engagement.

There are important reasons to focus on the school and school performance when considering children's mental health: According to a report by Santor et al. (2009), poor mental health or mental illness creates barriers to learning and success in school. They found that $14 \%$ of school dropouts are related to mental health disorders, children with mental health problems are absent for $40 \%$ more school days, and they achieve lower academic success than their mentally healthy peers. However, only a small fraction of children affected by mental illness have been diagnosed. In fact, studies indicate consistently that only one in six people who have a diagnosable mental illness will have access to mental health services through the health care system (Canadian Psychiatric Association, 2012).

\section{Learning Objective \#3}

Candidates will appreciate their role, responsibilities, and capabilities related to social justice, equity, and the value of being a caring adult in the lives of children.

The cornerstone of this course's curriculum was rooted in inclusive education, with a stance that all students belong and are part of the community (King et al., 2010). Most students with identified exceptionalities, including mental illness, spend considerable 
time in a regular classroom. It is important that we develop courses for teacher candidates that present this inclusive framework; as Specht et al. (2015) pointed out, "Preservice teacher education programs have a responsibility to graduate teachers who can teach in those classrooms" (p. 2).

Initial education for teaching offers a unique opportunity to engage new professionals as they develop their sense of identity as a teacher: In their study regarding mental health education in a pre-service teacher education program in the United Kingdom, Bostock, Kitt, and Kitt (2010) concluded, "This seems like a good time to capture them-before the experienced teacher habitus is formed" (p. 113). AskellWillams and Lawson (2013) echoed this in their evaluation of a school mental health effort in Australia and the ways in which qualified teachers were struggling with both their subjective (beliefs and values) and objective (knowledge and context) adequacy in being an effective part of a school-wide mental health effort: "The implication for preservice teacher training is clear, in that mental health promotion needs to be integrated into preservice teaching curricula" (p. 140).

The body of evidence about the impact of adverse childhood experiences on mental health in youth and young adults demonstrates the connections between most adverse childhood experiences (including exposure to family violence, child maltreatment, and having a parent with addictions) and mental health outcomes including depressive symptoms, substance abuse, and anti-social behaviour (Schilling, Aseltine, \& Gore, 2007). Alongside these findings are the body of evidence linking the social determinants of health to mental health outcomes, and the finding that, according to the World Health Organization and Calouste Gulbenkian Foundation (2014), "Certain populations subgroups are at higher risk of mental disorders because of greater exposure and vulnerability to unfavourable social, economic, and environmental circumstances, interrelated with gender. Disadvantage starts before birth and accumulates throughout life" (p. 9).

Using a social justice framework was important for challenging teacher candidates to examine the way they viewed students' behaviour and capability to do well in school. Sen's (1992) Capability Approach positions capability as the freedom to achieve what we value, such as an education or a good job, and points out that such freedoms are constrained for entire populations or groups of people because of a lack of access to resources. For example, the child who lives in poverty cannot access food on her own and relies on school breakfast programs to receive proper nutrition, and the youth who lives with mental illness needs the support of caring adults if she is to have the freedom to be engaged in her education.

\section{Learning Objective \#4}

\section{Candidates will develop mental health literacy to support the learning and growth-oriented} needs of children and youth.

In order to create classrooms that provide students with supports that address children's resiliency and mental well-being, teachers need to develop mental health literacy, which includes an enhanced understanding of how to obtain and maintain positive mental health (Kutcher \& Wei, 2014). While mental health literacy does not include expertise in mental health care, it does include the awareness, dispositions, 
beliefs, and values that are necessary first to orient educators to the needs of children and youth, and then to enhance their ability to support students' mental health in school (Weston et al., 2008).

Extending the support for mental health to schools and within the community culture is a first and important step in moving toward a more child-centred, holistic model of health (Tolan \& Dodge, 2005). Further, promoting mental health literacy among teachers can help Canadian children and youth to reach their potential (Whitley, Smith, \& Vaillancourt, 2013). Taking this school community approach to child and youth mental health has important implications not only for academic gains, but also for improvements in the health of the whole child and family, promotion of social skills, and significant systemic and personal financial savings (Schwean \& Rodger, 2013; Tolan \& Dodge, 2005).

\section{Learning Objective \#5}

Candidates will develop self-awareness to foster stigma reduction, capacity building, and engagement for mental health.

Healthy classrooms begin with healthy teachers. Teachers who are struggling with mental health problems or who work in places that are not conducive to workplace health and psychological safety will suffer more absenteeism, more stress, and more health problems (Kovess-Mastefy, Rios-Seidel, \& Sevilla-Dedieu, 2007; Szeto \& Dobson, 2013). Teacher education has been identified as a natural place to help teacher candidates develop self-awareness, knowledge, and skills that are connected with resilience (Alkins, Banks-Santilli, Elliott, Guttenberg, \& Kamii, 2006). In their review of the research on teacher mental health, Van Droogenbroeck and Spruyt (2015) concluded, "The idea that teachers have worse mental health than others is less conclusive than often assumed" ( $p$. 88). However, the research on how a teacher's mental health affects students is clear: Arens and Morin (2016), looking at data from nearly 400 teachers and 8,000 Grade 4 students in Germany, reported direct and negative relationships between teachers' emotional exhaustion and students' class average, standardized achievement test score, school satisfaction, and perceptions of teacher support. Further, a recent Canadian study detected a connection between students' stress levels (as measured by cortisol) and teacher self-reports of burnout (Oberle \& Schonert-Reichl, 2016).

Education to reduce stigma indicates that when we provide people with the opportunity to meet an individual who lives with mental illness, they become more empathic and understanding as they come to recognize the humanity in that individual. Most people can remember a time when they felt emotional distress-therefore, sharing in common experiences of sadness, preoccupation, anxiety, or fear can disrupt the tendency to "Other" individuals with mental illnesses (e.g., see Kumashiro, 2002). People come to recognize themselves in certain themes or occurrences in the stories of individuals who have lived with mental illness. This experience of empathy can also lead to action: Hearing about individuals' road to recovery from mental illness in spite of prejudicial barriers, marginalizing practices, and discriminatory obstacles can prompt teacher candidates to get involved with advocacy or pedagogical strategies that decrease stigma in the classroom (Corrigan, Roe, \& Tsang, 2011). 
Given this research literature, the need for more mental-health-related education at the pre-service level was established with the goal of enhancing teacher candidates' skills to meet the diverse needs of the students they will encounter. To address this need, we developed and evaluated a mental health education course for teacher candidates. The aims of this project were (a) to evaluate the first iteration of the course and teacher candidates' progress toward the five learning objectives, and (b) to invite teacher candidates to share their thoughts about what they were learning and about the personal and professional meaning of their learning.

\section{Method}

\section{Course Development and Format}

We completed the aforementioned review of courses available across Canada in teacher education programs, informally interviewing teachers, teacher educators, and teacher education students; and we surveyed the existing literature in three areas: effective pre-service teacher education for mentally healthy schools (Weston et al., 2008), mental health literacy (Kutcher \& Wei, 2014), and online learning and teaching. Specifically, we looked to the effective practices in professional teaching to guide our teaching approach. Examples of what guided us in the development of the learning objectives, and the teaching methods we employed for these objectives, are outlined below.

Course format. Course participants developed a variety of learning products as they progressed through a series of nine modules organized by topic. The topic schedule is found in Appendix A.

Class Photo and Learning Journal. We illustrated the socio-emotional contexts of diverse children by developing a fictional Class Photo featuring brief case studies of eight students living in one or more of these contexts. Teacher candidates each chose one student to follow throughout the course, which formed the basis for their Learning Journals (see Course Assessment for further details). We paralleled the natural development over time of a teacher's relationship with a student by revealing new information to teacher candidates each week about the student's life and experiences (see Appendix B for one example).

Become an Expert. In addition to following a child in the Class Photo, teacher candidates were asked to take on responsibility in becoming a local "expert" in one of eight important contextual areas: (a) students who are in care of child protection, (b) who live with a parent who abuses drugs or alcohol, (c) who live in poverty, (d) who are Aboriginal, (e) who are LGBT or have parents who are LGBT, (f) who are refugees, (g) who are in the juvenile justice system, or (h) have experienced family breakdown. A set of resources in each area was provided, and teacher candidates read through them.

Discussion Forum roles. Candidates were assigned to a small group for a weekly Discussion Forum using the jigsaw technique, such that one expert from each area of focus was in each group. Candidates were encouraged to bring their expertise to bear in weekly discussions so their peers could learn. For example, in the Week 2 discussion about understanding mental health and well-being, the candidates shared what they 
learned about the effect of poverty and pre-migration trauma on mental health for students. Weekly discussion questions used Stead's (2014) Reading and Analyzing Nonfiction strategy (R.A.N.; see Appendix C)

Modules. Using the five learning objectives presented in the introduction, we created nine modules, delivered weekly, planning the learning and assignments so that teacher candidates would spend an average of four hours completing one module and the related assignments (readings, viewing the presentations online, completing the Discussion Forum and Learning Journals). Modules were separated by a practicum block between Weeks 5 and 6.

Each week, teacher candidates worked through one online module, which included video presentations, assigned readings and exercises, web links from the website out to other resources and sources of information, online discussions, and the Class Photo updates.

Learning objective \#1. Learning objective \#1 (to learn about mental health for all children and youth) was supported by providing teacher candidates with an introduction to social-emotional learning and by exploring the contexts of diverse students, including Aboriginal students; newcomers to Canada with pre-migration trauma; students in foster care; and students living in families where there is violence, substance abuse, or poverty. We chose these contexts because each places children and youth at risk of mental health problems, with the risk rising substantially for children and youth from Aboriginal populations or living in adverse conditions (Burge \& Gough, 2007; Canadian Pediatric Society, 2009; Mental Health Commission of Canada, 2012).

Learning objectives \#2 and \#4. Learning objective \#2 (to learn about the impact of mental health on school performance) and \#4 (to develop mental health literacy) were supported by weekly presentations of materials to develop this knowledge. PowerPoint presentations with voice recordings, assigned readings, and brief videos were used to communicate information.

Learning objectives \#3 and \#5. Learning objective \#3 (developing an understanding of their role and capabilities as a teacher) and \#5 (self-awareness, decreasing stigma, building capacity, and increasing engagement in teacher candidates) were supported by two course elements: the Class Photo and the Discussion Forums. Each week, teacher candidates were required to read the new information gained in the Class Photo, and then reflect on how they might respond and support the student as their teacher. Such contact-based approaches, in which people have the opportunity to hear the story of an individual who has struggled with their mental health, have been shown to be effective in reducing stigma toward people with mental illness (e.g., Froese-Germain \& Riel, 2012).

As we discuss in the Results section, the third learning objective also developed as teacher candidates learned about the prevalence in Canadian classrooms of students struggling with mental health problems and felt called to articulate the role that they would play in the lives of their students. Finally, teacher candidates also had the opportunity to develop self-awareness through learning exercises that encouraged them to 
engage in self-reflection during weekly, asynchronous online discussions. According to Darling-Hammond (2000),

Developing the ability to see beyond one's own perspective, to put oneself in the shoes of the learner and to understand the meaning of that experience in terms of learning, is perhaps the most important role of universities in the preparation of teachers. (p. 170)

Weekly discussion questions using Stead's (2014) R.A.N. strategy (see Appendix C) encouraged candidates to think about how new information was congruent or incongruent with their own experience and prior learning, what misconceptions they identified, and how they were going to use their new learning though developing personal and professional actionable items.

We framed all of this with our collective knowledge and experience regarding effective teaching and learning (e.g., Kolb's Experiential Model; Kolb \& Kolb, 2005), as the team of course developers included education faculty members who are registered psychologists, a faculty member with expertise in both multi-literacies and elementary teaching, graduate students in education and counselling psychology, an undergraduate psychology student, and a recent graduate of the Bachelor of Education program.

\section{Participants}

Of the 39 teacher candidates in the class, seven agreed to participate in the research. Our sample included two men and five women; two participants - one man and one woman-identified as mature students. Only one participant identified herself as being born outside Canada. All were enrolled full time in the Bachelor of Education program and in the nine-week online course during the fall term of the 2013 academic year.

\section{Course Assessments}

Assignments were designed to maximize participation, reflection, and contributing to the learning of peers. Learning was assessed in these ways:

Participation (40\% of the total grade). Evenly split between two activities (the Learning Journal and the Discussion Forum), assessment was based on ability to respond thoughtfully within each activity, make connections, think critically, support the learning of their peers, communicate in a professional dialogue (which included negotiating differences), be engaged, and be responsible for taking and demonstrating initiative in the discussion in ways that fostered teamwork and a scholarly community of practice.

Learning Journal. Teacher candidates were required to take the voice of one of eight students from a Class Photo and to write two brief journal entries each week: one in the student's voice, and the other in their own voice as the student's teacher. Each week of the course, teacher candidates were provided with an update on the student they had chosen; these students' stories included context, recent events in the students' lives, and their experience in school that week.

Discussion Forum. Teacher candidates were placed into small groups of six during the first week of the course using a jigsaw technique, and each person in a group was 
designated an "expert" in children and youth in one of eight different areas: a) students who are in care of child protection, (b) who live with a parent who abuses drugs or alcohol, (c) who live in poverty, (d) who are Aboriginal, (e) who are LGBT or have parents who are LGBT, (f) who are refugees, (g) who are in the juvenile justice system, or (h) have experienced family breakdown. Support materials were provided on the class website. Teacher candidates were required, on a weekly basis, to respond to the discussion questions and post responses to at least one other group member's post, bringing this expertise to bear.

Individual project (30\%). The final (and individually completed) assignment was to develop a Resource Guide in the form of a 10 (or fewer)-slide presentation about mental health in schools that could be given at a staff meeting in 10 minutes or less. Teacher candidates were required to: introduce the topic (e.g., eating disorders); discuss how it could affect student learning; provide three teaching strategies for the classroom; and suggest links or locations of resources available at the local, provincial, and national levels. Please see Appendix D for a full description of this assignment.

Group project (30\%). Each group (from the weekly discussions) worked together on one of two case studies. Since this was a group project and data and contributions could not be attributable to any individual student, this assignment was not used as part of the data for the current study. A brief description is attached in Appendix E for interested readers.

\section{Pedagogical Approach}

Through the presentations, resources, assignments, and discussion we sought to "decrease the distance" between teacher candidates and their future students using learning tools like the Class Photo, Discussion Forum, and self-reflection to develop selfawareness and address any stigmatizing attitudes, values, or beliefs.

\section{Procedure}

Ethical approval was granted by the university's Research Ethics Board, and teacher candidates in the course were invited by a research assistant to participate by granting permission to access learning products (Discussion Forum, Learning Journals, and Resource Guide assignments) and to engage in an interview with the research assistant once the course was completed and grades had been posted. Interviews were about one hour in length, were audio-recorded and transcribed. Please see Appendix F for the interview questions.

Creswell's (2009) steps for qualitative data analysis guided the analysis process. First, data was organized and prepared beginning with transcription of the discussions. Next, the transcripts were reviewed and read thoroughly in order to gain a general sense of the data and stimulate reflection on the overall meaning. Questions such as, "What are these voices telling us?" and "What is the meaning behind the comments?" guided the reflection. Next, data organization began with the extraction of significant statements. Statements made by the participants that related to the overall theme of mental health literacy were selected and organized. The remaining data was reviewed multiple times by 
both researchers, together and independently, in order to identify broad themes. Because this was an evaluation of a course that had specific goals, we sorted the data into two themes: Expected and Unexpected learning outcomes. Quotations were selected to represent each theme and to bring the teacher candidates' voices to the forefront of the information. The themes and subthemes are outlined below (see Results).

\section{Results}

Based on the final grades of the course, we feel confident that all five of the mental health literacy learning objectives established for the course were achieved by the teacher candidates. The following average course grades were achieved (in all cases, the grades achieved by the class overall, compared to those who participated in this research, did not differ significantly): Participation 37.1/40 (92.7\%); Group Project: 27.5/30 (91.7\%); Individual Project: 25/30 (83.3\%); Final Overall grade: $89.1 \%$.

The remaining results refer to the learning outcomes demonstrated in the Discussion Forums, Learning Journals, and the responses to the interviews with the teacher candidates who took the course. Beyond meeting the learning objectives directly (e.g., "I learned that you can have a mental illness and have good mental well-being"), we entered into this analysis with the understanding that we would see evidence of expected outcomes (e.g., accounts of efforts to find out what mental health services exist in their schools), but also evidence of unexpected outcomes (e.g., accounts of advocacy and awareness by including mental health in their senior art curriculum during their practicum experience).

We expected to raise teacher candidates' awareness of the prevalence of mental illness in an average classroom, and teacher candidates responded with a sense of urgency to support struggling students. At the same time, we wanted to emphasize to teacher candidates that they did not have to be mental health experts - instead, they could draw on existing resources to help them help their students. We found that many teacher candidates also considered these resources as vital tools to support students. Other elements of teacher candidates' learning were generally expected, but not to the degree that teacher candidates demonstrated: We used self-reflection as a guiding principle throughout the course, but we did not anticipate how many teacher candidates would share their personal experiences of mental illness with their peers. We expected teacher candidates to use their Learning Journals to express empathy for their students, but we did not expect the complexity of the situations that the teacher candidates described, nor the depth of emotion teacher candidates expressed. One learning theme was unexpected: the trajectory of teacher candidates' learning from the beginning to the end of the course.

We begin this section by describing the learning outcomes that were expected.

\section{Expected Learning Outcomes, Based on Our Course Design}

Learning Objective \#1: Understanding mental health. The course allowed teacher candidates to correct two main misconceptions about mental health in the classroom. First, learning about the prevalence of students experiencing mental health problems in Canadian classrooms compelled teacher candidates to confront the reality that regardless of the subject or level they chose to teach-or the socio-economic status of the schools 
they hoped to teach in-they would likely be teaching students with mental health problems and diagnosed mental illnesses. One teacher candidate described her surprise at the prevalence of mental illness in the classroom:

Before starting this course, I did not realize how prevalent mental illnesses would be in my classroom one day. I assumed that I would have a student in poor mental health every few years, not a few students in every class!

Second, teacher candidates learned to distinguish between the concepts of mental health and mental illness. Prior to the course, many teacher candidates assumed that everyone had either mental health or a mental illness-for example, one teacher candidate described categorizing "mental illness and mental health problems to be very similar, if not the same." After learning the material in the course, this teacher candidate discovered that everyone experiences mental health problems from time to time, "whereas not everyone will experience a mental illness. I also did not realize that someone with a mental illness could have good mental health." This allowed teacher candidates to re-evaluate their own conceptions about what students with mental illness who also enjoyed good mental health could achieve in their classrooms.

Learning Objective \#2: The impact of mental health. Teacher candidates used their Learning Journals to uncover emotions, values, beliefs, and new understandings about how to support students with mental illnesses. We expected teacher candidates to express empathy through their Learning Journals, but we did not predict the degree of honesty they would express in their journals, nor the level of complexity they would bring to their stories when writing as a student and as a teacher. Teacher candidates expressed experiences of loneliness, pain, and suffering from the perspective of a student:

Sitting in the lunchroom, I can feel everyone staring at me, whispering, saying things about my family. I just want them to stop, and I want things to be back the way they used to be. Everyone thinks I'm "sweet little Caterina," always smiling and pleasing everyone, but don't people see that I'm sad? I hate life. I hate school and I hate being at home. I want to curl up in a ball and disappear. I've been at this school forever, and I know my teachers, and I know my friends, but I just feel so alone. Nobody knows or could possibly understand what I've been feeling.

... and from the perspective of a teacher:

I don't know how to handle this. I'm not a mental health professional. I think I'm putting too much pressure on myself to try and fix this. Maybe a call to the employee assistance line will benefit me. That way I can speak to someone about how I'm feeling.

I have recently found out that Caterina has been absent from school because she attempted suicide. I'm overwhelmed with emotion and pain for her. She is such a bright, beautiful young child, and I'm so sad that she felt death was her only option. I'm going to have to mention this to the class, but first I need to gain control of my own emotions.

Learning Objective \#3: The role of the teacher. Teacher candidates expressed a sense of duty and urgency to respond to the mental health of their students. First, teacher candidates learned about the inextricable link between mental health and academic success. One teacher candidate argued: "Because our founding responsibility is to educate students and support their welfare, an inability to recognize the impact that 
mental illness has on academics is also a failure to fully respond to the requirements for students' academic success." Next, learning about the influence of challenging contexts on students' mental health prompted teacher candidates to realize that, as one teacher candidate wrote, "I may be the only thing in their life that is constant."

These learnings compelled teacher candidates to define and develop the role that they planned to play in the lives of their students. For example, one teacher candidate concluded that "as teachers, I believe, it is our responsibility to be equipped with the knowledge and resources to identify and intervene [for] students under mental duress." Teacher candidates were encouraged by the number of resources they learned about to help struggling students-one teacher candidate remarked, "I now know that there is copious amount of literature, resources, organizations for teachers to use so that they may support their students' mental health."

Learning Objective \#4: Mental health literacy. Teacher candidates began the year with high confidence in their abilities to support students with mental illness. As the authors of this course, we expected to have to build their confidence in their ability to support students with mental illness. Given this, we expected to spend some time teaching course participants about the importance of building relationships with diverse students in their classroom. In contrast, at the beginning of the course (and the academic year), most teacher candidates were already confident about their abilities to teach and support students with mental illness. Many teacher candidates considered themselves to have a special calling for teaching, with some teacher candidates describing the calling as being passed down for several generations in their families. Many teacher candidates were also attracted to teaching based on positive experiences at school and with their teachers. One teacher candidate described what compelled her to pursue a career in teaching despite the limited number of full-time teaching jobs available:

From friends in other career paths, they don't understand why I would want to become part of a career that is currently so tough to break into. I tell them it's the passion. It's the fact that you had such a great high school experience, or university experience, or the fact that you love watching kids learn and grow and discover the world around them. I come from a family of teachers, from my mother and my father, to my aunt and even uncle. We're all involved in schooling. It's something that I believe you're born with-it's an inherent passion that you feel obligated to pursue to give future generations the wondrous experience you [had].

In retrospect, these teacher candidates' descriptions of their personal passion for teaching should not have been surprising, given the high academic standards required to be accepted to Bachelor of Education programs and the against-all-odds attitude necessary to enroll at a time when the full-time job market is extremely unfavourable for new teachers in southwestern Ontario. Most teacher candidates accepted into the program had experience profiles full of volunteer and paid positions working as camp counsellors, tutors, mentors, and sports coaches. For example, one teacher candidate explained that the multiple teaching roles that she held prior to enrolling in the teacher education program gave her the knowledge she needed as a future teacher:

$\mathrm{i}$ believe the most important thing one can bring to the class is experience, and through experience one becomes more knowledgeable. some of my personal 
experiences that particularly influence teachers, learning, relationships and expectations are my experience as a U16 co-ed soccer coach, my role as a Mentor in the [name of program] at [name of organization], and my opportunity to do observation placements at [three schools] the past three years.

This teacher candidate felt confident that taking good notes during teacher observation periods had given her the skills to be successful in her own classroom:

In my opportunity to observe teachers in various high schools, i made a lot of notes on how different teachers reacted to difficult situations brought about in the class, ranging from difficult class topics to student behavioural issues. i feel this experience will help me when i myself am faced with similar challenges in the classroom. i know that all situations are different and all students react differently, but $i$ am glad $i$ know various ways to respond and can choose which way i feel comfortable reacting.

As illustrated here, at the beginning of the academic year teacher candidates were undaunted by the prospect of inclusion for diverse students: They assumed that their previous experiences would be fundamentally similar to their role as a classroom teacher. As the course developers, we realized, then, that teacher candidates had to first go through the process of un-learning: They had to complicate their conceptions about the role of a teacher and the experience of a student with a mental illness, before they could understand what it meant to teach in a class with diverse needs. Teacher candidates learned this in two ways: online using the jigsaw technique, and in person during practicum.

Learning Objective \#5: Self-awareness, stigma reduction, and capacity building. Teacher candidates used the online forums to share and reflect on their personal experiences with mental health and mental illness. For example, one teacher candidate described his reluctance to seek help while struggling with his mental health after the death of his brother: "My brother was killed at an impressionable/volatile age for me and I did what most young men do and buried my emotions. Mental health was a sign of weakness - as you may know, the biggest stigma attached to it." He reflected that after hitting "rock bottom" and spending several weeks in an in-patient treatment program at a hospital, "I believe, through a lot of hard work and therapy with an amazing support team of professionals, that I'm stronger than ever." Although we considered reflection on teacher candidates' own experiences to be a guiding principle throughout the course, we did not expect teacher candidates to share candid, personal experiences of struggling with mental illness and maintaining mental health.

Teacher candidates described the tension between the benefits and drawbacks of a disclosure of mental illness. When conversing with her fellow teacher candidates in online discussions, one teacher candidate often described how important it was for her to make a personal connection with each student that extended beyond classroom instruction. However, when writing in her Learning Journal as "Todd" (a fictional Class Photo student struggling to come to terms with his parent's impending divorce), she poignantly captured the feelings of a student who assumed that teachers did not-or should not — care about the lives of their students outside the classroom:

I hate it when teachers get involved in my family and my personal life. They are just there to teach their class and be over with it. I don't need them to get involved in my personal life. Nobody cares, and the people who mention anything about my parents 
act like it's funny and they make fun of my family. Why does Ms. Smith think I'd want to talk to her about my problems? She doesn't know me, know my family, and she would never understand what I'm going through.

When writing as Todd's teacher, she also described a scenario in which the teacher's best efforts, failed ("Well, trying to talk to Todd didn't work"), but did not cause the teacher to give up on Todd. She distinguished between the behaviour that she saw ("He acts like he doesn't want anything to do with me and doesn't want anybody's help") and possible underlying reasons behind the behaviour ("He really doesn't have a support system at home"). She then empathized with Todd ("and having to act like the adult must be hard on him"), which caused her to re-evaluate her strategy. She described a multi-pronged approach that, in addition to re-approaching Todd, also included how she would respond to the rest of her class, and plans to reach out for support to other teachers at her school:

He knows that my door is open to talk, but maybe I need to get on his level more, and show him that I'm not just his teacher. I need to start showing the other kids how hurtful it is, and how they need to support Todd at this difficult time. I need to seek out my resources here at school and see if other teachers have dealt with this before, and see if they could help me at all.

These exercises in empathy also encouraged other teacher candidates to reconsider how they responded to troubling or challenging student behaviour:

My job is to be sensitive to students who are struggling with a mental illness and try to keep in mind that every student is struggling with something. I cannot assume that a student is just lazy or doesn't care about anything, because maybe there is more going on than I, or even they, realize. I need to be welcoming and approachable to every student so that if they or one of their friends is having a problem, they will feel comfortable talking to me about it.

Interestingly, teacher candidates also expressed their learning about the limits of empathy: Although teachers can imagine what their students are facing and how they feel, they can never presume to know for sure. Through exploring complex situations in their Learning Journals, teacher candidates learned how to moderate their instincts to respond first, then ask questions later. As they explored the possible results of presumptive actions, they began to understand the value of listening to understand students' experiences, rather than giving advice to direct students' behaviours.

Even though I may be able to "understand" some of what a student is experiencing, the journals helped me to better realize that my language may be misinterpreted or lead to negative results. I learned that I must make a distinction between support and advice, avoiding the latter. As educators, we must listen as much as we teach, but gauging a student's perspective towards academics, social settings, family life, etc., is necessary only for awareness of a situation and to identify the best resources to offer.

\section{Unexpected Learning Outcomes}

Teaching each other. Teacher candidates used the jigsaw technique to teach and learn from each other's "expert" portfolios, and used peer teaching and learning to apply critical thinking to their peers' proposed interventions for students and families experiencing mental illness. Class Photo profiles and the unfolding nature of the scenarios grounded the 
suggested interventions in a context-rich narrative, which helped teacher candidates become more comfortable with complex situations for which prescribed solutions are not written in any textbook. Teacher candidates were much quicker to take a critical eye to suggested interventions when they realized that they came in conflict with a student's personal background. This encouraged teacher candidates to purposely complicate theoretical solutions and to try them on for size in their students' context.

Connecting learning to the realities of classroom experiences. Teacher candidates had to experience for themselves what it felt like to juggle competing priorities between and among students, to face a scarcity of resources or social capital when helping students in need, and to respond to grey areas where students would demonstrate troubling or confusing behaviours, despite teacher candidates having learned previously about students with similar difficulties. At the same time, many also experienced how a supportive teaching culture of responding compassionately to students positively impacted these students' academic outcomes. For example, one teacher candidate reflected on her practicum experience teaching in a "downtown school in a small town," which she described as having many students with "difficult home lives":

Despite numerous behavioural issues and low motivation, these students had maintained a school culture that I have never experienced or heard of in a secondary school. The students have inordinate amounts of resiliency and acceptance for one another. Situations that would make myself fear for a long-time nickname were treated with compassion and sincere concern. The students supported each other and accepted each other despite the various differences and difficulties.

Unlearning. We did not anticipate the unlearning process that had to occur in order to reset teacher candidates' expectations and ideas about their role in the classroom. This was in contrast to the learning process we expected to see: We expected to have to build teacher candidates' confidence about their abilities to help students with mental illness in their classrooms. Instead, teacher candidates had to experience the ways in which they were not mental health experts in order to learn truly effective inclusion practices for diverse students, including those with mental illnesses.

\section{Discussion}

Teacher education programs are being called upon to respond to the needs presented by the community (Darling-Hammond, 2006), and these needs include supporting students' mental health (Santor et al., 2009) and building resilience to stress and burnout in emerging teachers (Arens \& Morin, 2016). The challenges to mental health faced by Canadian children, youth, and their teachers - and the impact that poor mental health has on learning and work - mean that we must address mental health education explicitly and with all the resources that can be brought to bear. Research indicates the efficacy of programs to shift in-service teachers' knowledge, beliefs and attitudes about mental health (Jorm et al., 2010; Kutcher \& Wei, 2014), but there are important reasonsincluding the efficacy of such efforts - to provide this learning to teacher candidates in their initial teacher education programs (Bostock et al., 2011).

Developing a mental health literacy course in response to this urgent need is a combination of content, pedagogy, and opportunity that allows teacher educators to 
provide candidates with the best possible foundation to a teaching career. Designing the course so that teacher candidates can reflect on and be aware of their own mental health and can develop coping skills and strategies may be beneficial to them as they begin their careers. As suggested by Arens and Morin (2016) in their study linking teacher emotional exhaustion to student outcomes, we can help new or future teachers mitigate the negative effects of professional work demands by raising their awareness of the signs, determinants, and consequences of burnout and the availability of support systems and coping strategies.

Our results demonstrate that this teacher education course on mental health was a valuable response to a need for more knowledge, awareness, and resources for teacher candidates to support their own and their students' mental health. The teacher candidates not only reflected the expected learning outcomes, but extended them and shared unexpected outcomes as well. We believe that mental health literacy for teacher candidates must include: (a) knowledge about mental illnesses that teachers will commonly encounter in the classroom; (b) the contextual experience of students who may be at risk of developing a mental illness or currently experiencing mental distress; (c) strategies and tools that are evidence-informed and responsive to students' mental health needs; (d) an understanding of how to develop and maintain teachers' own mental health, and how to ask for help when teachers need it; and (e) an opportunity for teacher candidates to engage in self-reflection to understand their own context including the attitudes, beliefs, emotions, prior experiences, and assumptions that they bring with them to their teacher education program. This self-reflection should continue throughout the course, including before and after practicum, so that teacher candidates can examine how their perceptions and understanding of their role in promoting mental health in the classroom evolves as they progress through coursework; can try out ideas during practicum; and can receive feedback from their teachers, peers, and students.

Teaching a mental health literacy course online may provide additional benefits to teacher candidates: We found that teaching this course online linked two seemingly contradictory outcomes: (a) providing a sense of anonymity, where participants felt more comfortable disclosing personal or sensitive information, and at the same time - or as a result, (b) helping develop a sense of community among teacher candidates during the course. Doring, Hodge, and Heo (2014) also found that graduate students were more willing than undergraduate students to share personal information with their teachers, teaching assistants, and classmates in online forums according to how they wished "to actively participate in a social learning environment" (p. 170). It could be that teacher candidates in this study shared characteristics with the graduate students in Doring et al.'s study because both groups had completed an undergraduate degree prior to this online course and were motivated to submit frequent and in-depth online posts. Teacher candidates may have chosen to disclose their personal experiences in order to create a social learning online environment that encouraged their peers to explore, ask difficult questions, and learn from each other about the role of mental health and mental illness in schools.

The limitations of this study include: a small sample size; not taking into account any learning or experiences during this time period that may have happened outside of this particular course and may have influenced learning; and the presumptions associated not only with the selection of the learning objectives we developed, but also with the 
assessment of attainment of the learning objectives. As a pilot study, however, it identifies important future directions for research and practice.

Moving forward, we recommend that more research be conducted to focus on the potential benefits of mental health literacy instruction and the connection to attrition and the experience of stress or burnout among new teachers. In doing so, we must continue to advocate for teacher education, because of the importance of this foundation to the thousands of young lives a teacher will influence over her career and the appreciation that education plays a gatekeeper to success in employment, financial independence, and healthy living. In preparing new teachers to take on a role that is complex, demanding, and inclusive, teacher education on the topic of mental health can not only result in more knowledge that will be helpful to both them and their students, but also encourage inclusive attitudes and practices for all students.

\section{References}

Adelman, H. S., \& Taylor, L. (2000). Promoting mental health in schools in the midst of school reform. Journal of School Health, 70(5), 171-178. doi:10.1111/j.1746-1561.2000.tb06467.x

Alkins, K., Banks-Santilli, L., Elliott, P., Guttenberg, N., \& Kamii, M. (2006). Project QUEST: A journey of discovery with beginning teachers in urban schools. Equity and Excellence in Education, 39(1), 65-80.

Arens, A. K., \& Morin, A. J. S. (2016). Relations between teachers' emotional exhaustion and students' educational outcomes. Journal of Educational Psychology, 108(6), 800-813. doi:10.1037/edu0000105

Askell-Williams, H., \& Lawson, M. J. (2013). Teachers' knowledge and confidence for promoting positive mental health in primary school communities. Asia-Pacific Journal of Teacher Education, 41(2), 126-143.

Bostock, J. A., Kitt, R., \& Kitt, C. (2011). Why wait until qualified?: The benefits and experiences of undergoing mental health awareness training for PGCE students. Pastoral Care in Education 29(2), 103-115.

Bryer, F., \& Signorini, J. (2011). Primary pre-service teachers' understanding of students' internalising problems of mental health and wellbeing. Issues in Educational Research, 21(3), $233-258$.

Burge, P., \& Gough, P. (2007). Prevalence of mental disorders and associated variables among Ontario children who are permanent wards. CECW Research in Brief \#3. Toronto, ON: Faculty of Social Work, University of Toronto. Retrieved from www.cecwcepb.ca/DocsEng/RIBMentalDisorders3E.pdf

Canadian Pediatric Society. (2009). Are we doing enough? A status report on Canadian public policy and child and youth health. Ottawa, ON: Author. Retrieved from http://www.cps.ca /English/Advocacy/StatusReport2009.pdf

Canadian Psychiatric Association. (2012). Youth and mental illness. Retrieved from http://publications.cpa-apc.org/browse/documents/20

Corrigan, P. W., Roe, D., \& Tsang, H. W. (2011). Challenging the stigma of mental illness: Lessons for therapists and advocates. West Sussex, UK: John Wiley \& Sons.

Creswell, J. W. (2009). Research design: Qualitative, quantitative, and mixed methods approaches. New York, NY: Sage Publications. 
Crocker, R., \& Dibbon, D. (2008). Teacher education in Canada. Kelowna, BC: Society for the Advancement of Excellence in Education.

Darling-Hammond, L. (2000). Constructing 21st-century teacher education. Journal of Teacher Education, 57(3), 300-314.

Doring, A., Hodge, A., \& Heo, M. (2014). Online learners and their self-disclosure preferences. Journal of Information Technology Education: Research, 13, 163-175.

Ellis, M., \& Riel, R. (2014). Work-life balance: Teachers identify four key areas. Perspectives, 15 (October). Retrieved from http://perspectives.ctf-fce.ca/en/article/3051/

Flett, G. L., \& Hewitt, P. L. (2013). Disguised distress in children and adolescents "flying under the radar": Why psychological problems are underestimated and how schools must respond. Canadian Journal of School Psychology, 28(1), 12-27.

Froese-Germain, B., \& Riel, R. (2012). Understanding teachers' perspectives on student mental health: Findings from a national survey. Ottawa, ON: Canadian Teachers' Federation.

Government of Ontario. (2012). Moving on mental health: A system that makes sense for children and youth. Retreived from the website of the Ministry of Children and Youth Services, http://www.children.gov.on.ca/htdocs/english/documents/specialneeds/mentalhealth /momh.pdf

Gowers, S., Thomas, T., \& Deeley. S. (2004). Can primary schools contribute effectively to Tier 1 child mental health services? Clinical Child Psychology and Psychiatry, 9(3), 419-425.

Ingersoll, R., Merrill, L., \& Stuckey, D. (2014). Seven trends: The transformation of the teaching force, updated April 2014. CPRE Report (\#RR-80). Philadelphia, PA: Consortium for Policy Research in Education, University of Pennsylvania. Retrieved from http://cpre.org/sites /default/files/workingpapers/1506_7trendsapril2014.pdf

Johnson, S., Cooper, C., Cartwright, S., Donald, I., Taylor, P., \& Millet, C. (2005). The experience of work-related stress across occupations. Journal of Managerial Psychology, 20, 178-187. doi:10.1108/02683940510579803

Jorm, A. F., Kitchener, B. A., Sawyer, M. G., Scales, H., \& Cvetkovski, S. (2010). Mental health first aid training for high school teachers: A cluster randomized trial. BMC Psychiatry, 10(51), 112. doi:10.1186/1471-244X-10-51

Kessler, R. C., Berglund, P., Demler, O., Jin, R., Merikangas, K. R., \& Walters, E. E. (2005). Lifetime prevalence and age-of-onset distributions of DSM-IV disorders in the national comorbidity survey replication. Archives of General Psychiatry, 62, 593-602.

King, G., Specht, J., Bartlett, D., Servais, M., Petersen, P., Brown, H., Young, G., \& Stewart, S. (2010). A qualitative study of workplace factors influencing expertise in the delivery of children's education and mental health services. Journal of Research in Interprofessional Practice and Education, 13, 265-283.

Kolb, A. Y., \& Kolb, D. A. (2005). Learning styles and learning spaces: Enhancing experiential learning in higher education. Academy of Management Learning \& Education 4(2), 193-212.

Koller, J. R., \& Bertel, J. M. (2006). Responding to today's mental health needs of children, families and schools: Revisiting the preservice training and preparation of school-based personnel. Education and Treatment of Children, 29(2), 197-217.

Kovess-Mastefy, V., Rios-Seidel, C., \& Sevilla-Dedieu , C. (2007). Teachers' mental health and teaching levels. Teaching and Teacher Education: An International Journal of Research and Studies, (23)7, 1177-1192. 
Kumashiro, K. (2002). Chapter 2: Theories and practices of anti-oppressive education. In K. Kumashiro (Ed.), Troubling education: Queer activism and anti-oppressive pedagogy (pp. 32-74). New York, NY: Routledge Falmer.

Kutcher, S., \& Wei, Y. (2014). School mental health literacy: A national curriculum guide shows promising results. Education Canada, March 2014. http://www.cea-ace.ca/educationcanada/article/school-mental-health-literacy

Mental Health Commission of Canada. (2012). Changing directions, changing lives: The mental health strategy for Canada. Calgary, AB. Retrieved from www.mentalhealthcommission.ca

Oberle, E., \& Schonert-Reichl, K. A. (2016). Stress contagion in the classroom? The link between classroom teacher burnout and morning cortisol in elementary school students. Social Science \& Medicine 159, 30-37.

Ontario College of Teachers. (2014). Accreditation resource guide. Toronto, ON: Author. Retrieved from https://www.oct.ca/-/media/PDF/Accreditation\%20Resource\%20Guide/2014_Accreditation _Resource_Guide_EN_WEB.pdf

Rodger, S., Hibbert, K., Leschied, A., Pickel, L., Stepien, M., Atkins, M.-A., ... Vandermeer, M. (2014). Mental health education in Canada: An analysis of teacher education and provincial/territorial curricula. Ottawa, ON: Physical and Health Education Canada. Retrieved from http://www.phecanada.ca/sites/default/files/mentalhealtheducationincanada.pdf

Rothi, D. M., Leavey, G., \& Best, R. (2008). On the front-line: Teachers as active observers of pupils' mental health. Teacher and Teacher Education, 24, 1217-1231.

Santor, D., Short, K. H., \& Ferguson, B. (2009). Taking mental health to school: A policy-oriented paper on school-based mental health for Ontario. Ottawa, ON: Provincial Centre of Excellence for Child and Youth Mental Health, Children's Hospital of Eastern Ontario.

Sen, A. (1992). Inequality re-examined. Cambridge, MA: Harvard University Press.

Schilling, E. A., Asletine, R. H., \& Gore, S. (2007). Adverse childhood experiences and mental health in young adults: A longitudinal survey. BMC Mental Health, 7(30). doi:10.1186/1471-2458-7-30

Schwean, V., \& Rodger, S. (2013). Children first: It's time to change! Mental health promotion, prevention and treatment informed by public health, and resiliency approaches. Canadian Journal of School Psychology, 28(1), 136-166.

Specht, J., McGhie-Richmond, D., Loreman, T., Mirenda, P., Bennett, S., Gallagher, T., Young, G., ... Cloutier, S. (2015). Teaching in inclusive classrooms: Efficacy and beliefs of Canadian preservice teachers. International Journal of Inclusive Education, 20(1), 1-15. doi:10.1080/13603116.2015.1059501

Stead, T. (2014). Nurturing the inquiring mind through the nonfiction read-aloud. The Reading Teacher, 67(7), 488-495. doi:10.1002/trtr.1254

Szeto, A., \& Dobson, K. (2013). Mental disorders and their association with perceived work stress: An investigation of the 2010 Canadian Community Health Survey. Journal of Occupational Health Psychology, 18(2), 191-197.

Tolan, P. H., \& Dodge, K. A. (2005). Children's mental health as a primary care and concern: A system for comprehensive support and service. American Psychologist, 60, 601-614.

Van Droogenbroeck, F., \& Spruyt, B. (2015). Do teachers have worse mental health? Review of the existing comparative research and results from the Belgian Health Interview Survey. Teaching and Teacher Education, 51(1), 88-100.

Weist, M. D., Lever, N. A., Bradshaw, C. P., \& Owens, J. S. (2013). Handbook of school mental health: Research training, practice and policy. New York, NY: Springer. 
Weston, K., Anderson-Butcher, D., \& Burke, R. (2008). Developing a comprehensive curricular framework for teacher preparation in expanded school mental health. Advances in School Mental Health Promotion, 1(4), 25-41.

Whitley, J., Smith, J. D., \& Vaillancourt, T. (2013). Promoting mental health literacy among educators: Critical in school-based prevention and intervention. Canadian Journal of School Psychology, 28, 58-70.

World Health Organization \& Calouste Gulbenkian Foundation. (2014). Social determinants of mental health. Geneva, Switzerland: World Health Organization. Retrieved from http://apps.who.int /iris/bitstream/10665/112828/1/9789241506809_eng.pdf

\section{Disclosure}

The authors and their research programs are not in any way affiliated with or funded by the makers or distributors of any product named in this article. Brand names are reported only for the purpose of factual accuracy, and our use of such products for research purposes does not constitute an endorsement of any particular brand or vendor.

\section{Authors' Note}

Correspondence concerning this article should be addressed to Melanie-Anne Atkins, University of Western Ontario, University Community Centre, Room 76, London, ON, N6A 3K7, Canada. Email: matkin4@uwo.ca 


\section{Appendix A: Course Topics}

\begin{tabular}{|c|c|c|}
\hline Week & Topic & Materials and Resources \\
\hline 1 & The Lives of Children & Online presentations \& readings \\
\hline 2 & $\begin{array}{l}\text { Understanding Mental } \\
\text { Health and Well-Being }\end{array}$ & $\begin{array}{l}\text { Videos and presentations about the developing brain, } \\
\text { the importance of caring relationships, language and } \\
\text { health; the dual continuum model of mental illness and } \\
\text { wellness }\end{array}$ \\
\hline 3 & $\begin{array}{l}\text { Mental Health } \\
\text { Challenges }\end{array}$ & $\begin{array}{l}\text { Online presentations about common mental health } \\
\text { challenges for children and youth, handouts, and a talk } \\
\text { regarding the role of the teacher }\end{array}$ \\
\hline 4 & $\begin{array}{l}\text { Stigma and } \\
\text { Discrimination }\end{array}$ & $\begin{array}{l}\text { Presentation including voices from people experiencing } \\
\text { mental illness and who are flourishing, social justice, } \\
\text { and where we learn about mental illness (e.g., media) }\end{array}$ \\
\hline 5 & $\begin{array}{l}\text { Experiences With Mental } \\
\text { Health Challenges }\end{array}$ & $\begin{array}{l}\text { Video and online presentation about mental illness, non- } \\
\text { suicidal self-injury, resources, and student awareness } \\
\text { and advocacy. }\end{array}$ \\
\hline 6 & $\begin{array}{l}\text { Seeking Help and } \\
\text { Finding Support }\end{array}$ & $\begin{array}{l}\text { Online presentations, videos, and readings to support } \\
\text { understanding the pathway to care in schools; } \\
\text { confidentiality; support; and the ways teachers can } \\
\text { collaborate with students, families, and professionals for } \\
\text { student wellness. }\end{array}$ \\
\hline 7 & $\begin{array}{l}\text { The Value of Mental } \\
\text { Health and Well-Being }\end{array}$ & $\begin{array}{l}\text { Online presentations, videos, and readings on building } \\
\text { resilience and self-confidence for self and students, } \\
\text { creating mentally healthy classrooms }\end{array}$ \\
\hline 8 & $\begin{array}{l}\text { Linking Violence and } \\
\text { Mental Health } \\
\text { Adjustment }\end{array}$ & $\begin{array}{l}\text { Online presentations, videos, and readings about the } \\
\text { connection between child maltreatment and learning } \\
\text { problems, and mental health, and about how to consider } \\
\text { curriculum resources and teaching methods for use with } \\
\text { students who have these experiences. }\end{array}$ \\
\hline 9 & $\begin{array}{l}\text { Responding to Mental } \\
\text { Health Needs }\end{array}$ & $\begin{array}{l}\text { Readings and strategies, stories from experienced } \\
\text { teachers, and video presentations. }\end{array}$ \\
\hline
\end{tabular}

\section{Appendix B: Abbreviated Class Photo Example}

\section{Todd (Weekly Updates)}

Week 1. Todd is a 16-year-old Caucasian male from a quiet urban Ontario community where a large part of his maternal extended family lives. The oldest child of three, Todd has a younger sister and brother. Todd began seeing his guidance counsellor before summer began, as he noted that his parents "haven't been getting along" and he believes that it is taking a toll on him and his younger siblings. Todd notes that they both work "demanding" jobs and come home tired and grumpy. Todd has noticed the feelings of sadness and anxiety that he and his siblings experience after one of his parents' "yelling matches"; and to help cope with it, he writes stories with his brother and sister at the park, or chats online with his girlfriend. 
Week 2. You've noticed that Todd has fallen asleep in your class a few times this week. He is usually an exceptionally attentive student, eager to participate and contribute to class discussions. After the third day in a row of Todd falling asleep you decide to ask him if he's feeling ok. He mentions that he's "not been getting much sleep lately" and assures you that it won't happen again. Despite being a social butterfly at school last year, you've seen that Todd seems to be spending his lunch periods with his younger siblings, avoiding speaking with his friends. What do you think could be going on here?

Week 3. Out of character, Todd missed two days of your class this week. You call home to speak with Todd's mother, who is disappointed to hear that Todd has missed school, but admits that it is not surprising. She goes on to explain Todd's father has recently moved out of the house. She knows that Todd has been making a significant effort to protect his younger siblings from the fallout of his parents' separation, and is concerned over Todd's behaviour changes as well. She explains that because of her work schedule the kids get themselves to school in the morning. Do you think this information will help you? How? How can you help Todd attend school regularly?

Week 4. It's the fourth week of class and Todd's behaviour continues to become more and more inconsistent with the student you remember from last year. Earlier this week he punched one of his old friends in the face during the lunch hour break when the friend shouted at him "Your mom is a dyke!" In the principal's office Todd explains that his parents separated over the summer, after his mother came out to her family as a lesbian; he was suspended for his violent outburst. You watch the following video to try to understand what Todd is experiencing: https://www.youtube.com/watch?v=Z9xfHqT1HEY

Week 5. Todd is back in school following his suspension. You pull him aside after class to discuss the work he has missed while away from class and help him get back on track with his work. He sits slouched over in his chair, staring at the floor, not responding. Before he leaves you mention to him that you'd heard from his mother that his parents had recently separated and say, "Todd, these things are difficult for anybody experiencing them. If you ever feel the need to talk about it or just want to drop by to vent for a bit, feel free to talk to me." You dismiss Todd, but reiterate that your door is always open if he needs anything. What could be going on with Todd? Is there anything you could do to help him? If so, what?

Week 6. You're working on some lesson planning during one of your prep periods this week when you hear a knock on the door. It's Todd. The two of you sit in silence for a few minutes before Todd looks up with teary eyes and says, "Can I just hang out for my spare so that I can get some work done?" You say, "Todd, you're welcome to come here during your free periods to work as long as you knock on the door when you come by. If I'm planning on working somewhere besides this room then I can't have you in here by yourself." For the rest of the period Todd sits at his desk with a book, but is not reading. When the bell rings, Todd gets up to leave and you say, "Todd, I'm happy to have you come by here to work if you want. I just wanted to let you know that if there's ever anything else you want to talk about then I'm here." Todd says, "Appreciate it. I'll see you later." Todd chooses to spend his free period in your classroom for three out of the remaining four days of the week, never saying much. Why do you think he keeps coming to spend his free periods in your class? What can we do for students who appear to be struggling, but unwilling or unable to speak about it? 
Week 7. Todd didn't show up to hang out in your classroom during the first few days of this week but eventually turns up. You welcome him in; Todd sits down at a desk in the front row, biting his lip and looking at everything in the room except for you. "What's up Todd?" Todd sighs softly before saying "Life sucks," and he begins to share with you all of the frustrations he's been experiencing at home. He tells you how he doesn't get to spend very much time with his father anymore and doesn't know what to think of his mother, who has recently disclosed that she is gay. He loves his mom but is angry with her for "breaking up the family." On top of all this he's been being teased at school about his mother's sexuality. He doesn't feel like he can talk to any of his family or friends about this, and states that it's causing him a lot of stress and frustration. You ask him how he's doing and what he'd like to do now. He tells you that he feels a lot better after telling you, but isn't sure what to do next. How do you react to everything Todd has told you? What can you do for Todd?

Week 8. You've been thinking a lot about your last interaction with Todd and realize that he may benefit from speaking with the school counsellor. The next time you see him he thanks you for letting him hang out in the class. You respond telling Todd not to worry about it, that you're here to listen any time he wants, but realize that this is becoming more than you can help with. "Todd," you say tentatively, "I'm hearing that this is a really tough time in your life right now, and I can't believe how well you're doing with all the recent changes you've gone through. I think anyone in your situation would be having a tough go of it ... I'm happy to sit down and talk whenever I can, but I can't guarantee that I'll always be available, or know what to say. Have you ever considered making an appointment with a school counsellor?" Todd looks up at you, pondering for a moment. It's as if he's trying to figure out what you're thinking. "Ya, my parents have been trying to get me to make an appointment for the last little while. I'm not really sure what to think about it. I'm not crazy or anything, you know?" Together Todd and you discuss reasons why people might go to see a counsellor besides being "crazy." Todd says that he'll think about it and leaves for class.

Week 9. It's been a week since you and Todd spoke about him making an appointment with a school counsellor. Today you receive an email from Todd's mother. "I just wanted to thank you so much for everything you've done over the last couple of weeks for Todd. His father and I have both been trying to get him to talk about what's been bothering him, but he's preferred to lock himself in his bedroom and ignore us. As time went on it became clear that you were someone he deeply respects, and the fact that you were giving him the space and time to vent about what's been going on in his life, and giving the respect right back to him has made all the difference in the world. He's made an appointment with a school counsellor. I know that everything's not 'better,' but at least now I know that Todd is going to have someone to talk to outside of the family, both in his new counsellor and you. Thank you." You're deeply touched by this email. You never thought that you were doing anything special for Todd, just giving him the "time of the day," so to speak. You sit at your desk pondering how small actions can lead to profound consequences. How did you help Todd over this semester? 


\section{Appendix C: Discussion Forum Questions}

\section{(Answered each week)}

Teacher candidates completed the following questions before and after each week's module, as adapted from the Reading \& Analyzing Nonfiction strategy (R.A.N. strategy; Stead 2014). Teacher candidates were asked to elaborate on the following:

1. What I think I know (before the module)

2. Fact confirmed (confirming prior knowledge stated in \#1)

3. Misconceptions (discarding or modifying knowledge about \#1 based on learning during the module)

4. New facts/information (thinking about information that is new to their learning, not covered under \#1).

5. Wonderings (questions generated as a result of learning in the module)

\section{Appendix D: Individual Project (Resource Guide)}

In this assignment, students will put together a set of resources that they might use in their roles as teachers and share with colleagues in a work setting. The resource guide must be tailored to one specific community (ideally, the community where you hope to begin your teaching career) and include resources that address the whole child perspective to mental health and well-being. The resource guide should also include some provincial and national resources and provide information, sources for support and resources, and strategies/practical applications for classroom teachers. More information will be provided.

Here are the details:

You may use Powerpoint, Prezi, or Glogster (glogster.com-it's free) to create a presentation that you would give to your staff team at your school (the school where you have done, or will do, practicum, or the school where you would like to work). You can focus on one type of mental health problem (for example, suicide, eating disorders, depression, etc.), or talk in more general terms about mental illness-I will leave that up to you. Whichever of the three methods you choose, you must:

- Set the stage - introduce the topic (specific or general, as you choose), talk about prevalence, and why this is important.

- Talk about how mental illness and well-being impact learning, academic engagement, and other types of desirable outcomes for children and youth.

- Introduce at least three strategies that teachers can use in their classroom to support students who are struggling.

- Introduce two national or provincial resources and at least two resources from your local school board (this could be the guidance department, Behaviour Team, whatever you can find that is in place) and community. Note: You can do two resources from the school board, or one from the school and one from the community.

If doing a Powerpoint or Prezi, it should be about 10 slides, maximum. If doing a Glogster, provide the information through titles, and then links to the appropriate places. 
For Prezi and Glogster (both stored online), you can "share" it with me on their website. For Powerpoint, use the Dropbox on this site. Using any of the three media, please use Dropbox for your 1-page outline (below).

Provide me with a 1-page (single or double-spaced) outline that you would use as your speaking notes, and divide it into these sections:

1. Key Messages: In point form, outline what you want people to learn from your presentation.

2. Features of my school that I have to be aware of (e.g. rural or urban, cultural diversity, remote location, etc.)

3. Motivation: How will you encourage people to engage in your presentation, be open to the topic and perhaps learn something new, and build a sense of community around this topic?

\section{Appendix E: Group Project (Case Studies)}

In response to one of two case studies, work with your team to develop a plan to address the concerns and create positive change. Required (for either case study):

1. A three-page review of evidence-based practices and published literature about what teachers, schools, and/or a school-based mental health approach could contribute to address the issue.

2. An annotated bibliography of resources, sources, and tools that you would use in addressing the issue. This will include resources from "your" school board.

3. A three-page summary that contains the following sections:

- Perspective

- Goals

- Partners

- Action plan

- Resources (those needed, those available)

- Strategies (must be directly related to overall goals and related to the action plan)

The final product should not exceed 10 pages, double spaced.

\section{Case Study 1-The Suicide of a Student}

Your group represents the department heads at a comprehensive secondary school in an affluent suburb. Most students are under considerable pressure to succeed academically, attend university, and have successful careers; in fact, most of the students are concentrated in the university stream program. The school deals regularly with alcohol and drug use, but overall the attitude from the school leadership (and parent group) is that "kids will be kids." During a recent graduation party two students took their lives by deliberate drug and alcohol overdose. These students were not known to be troubled or any different, really, than any of the other students. In preparation for the new fall term, your team has been asked to come up with a plan to help students cope, prevent such tragedies in future, and identify students who may be at risk for substance abuse and suicide. 


\section{Case Study 2-An Atmosphere of Despair}

Your group represents the department heads at a small comprehensive secondary school in a rural, and fairly remote, area. The local school board offices are more than two hours away, and the community is small, with few resources other than those devoted to municipal affairs, child welfare, employment, and emergency medicine. The school is positioned near an Aboriginal community, and most students' parents are either unemployed or underemployed because of the economic downturn. During the past year there have been a number of violent acts, including assaults, hate graffiti, and bullying, that seem to be focused on racial, and perhaps economic, differences. Attendance is suffering, and academic achievement is headed in the wrong direction. Many students seem afraid or aggressive. Sometimes it seems like everyone is just tired, nervous, depressed, and disengaged - even the staff! It seems like there is a loss of hope for many students, and there have been an alarming number of students who have sought emergency services at the hospital for anxiety and depression. Your group has been asked to come up with a school-wide plan to address these problems, and to include ways in which the school community can cope with what is going on and build toward a happier and healthier future.

\section{Appendix F: Interview Questions}

\section{(Interviews completed in person, one-on-one, after the course was completed)}

1.) Having now completed this course, how do you feel that your capacity to respond to student mental health needs has changed...

(a) on a cognitive/knowledge-based level?

(b) on a motivational/skill-based level?

(c) on an emotional level?

(d) on a social/relational level?

2.) What things did you feel were done well/not well in this course?

3.) Can you think of any changes you would make to this course to improve it going forward? 